\title{
INFLUÊNCIA DA MASSA ESPECÍFICA APARENTE DA MADEIRA NO RUÍDO PRODUZIDO DURANTE O PROCESSAMENTO SECUNDÁRIO: ESTUDO DE CASO
}

\author{
Nilton César Fiedler ${ }^{1}$, José Tarcísio da Silva Oliveira ${ }^{1}$, Pompeu Paes Guimarães ${ }^{2}$, \\ Rafael Tonetto Alves ${ }^{2}$, Fernando B. Wanderley ${ }^{2}$, José Geraldo Lima de Oliveira ${ }^{3}$, Rômulo Mora ${ }^{2}$ \\ ${ }^{1}$ Eng. Florestal, Dr., Depto. de Engenharia Florestal, UFES, Alegre, ES, Brasil - fiedler@pq.cnpq.br - jtsilva@npd.ufes.br \\ ${ }^{2}$ Graduando em Engenharia Florestal, UFES - Alegre, ES, Brasil - pompeupaes@yahoo.com.br - rafatonetto@ gmail.com - \\ fernandobwef@gmail.com - romulomef@yahoo.com.br \\ ${ }^{3}$ Eng. Agrônomo, Mestrando em Produção Vegetal, UFES, Alegre, ES, Brasil - josegeraldo@ yahoo.com.br
}

Recebido para publicação: 23/11/2007 - Aceito para publicação: 05/08/2008

\begin{abstract}
Resumo
Esta pesquisa teve como objetivo analisar o ruído produzido durante o processamento de distintas madeiras e a sua correlação com a massa específica aparente. As espécies utilizadas foram kiri (Paulownia sp.), eucalipto1 (Eucalyptus grandis versus E. urophylla (híbrido urograndis)), eucalipto 2 (Eucalyptus sp.), angelim-pedra (Hymenolobium petraeum), cedro (Cedrela fissilis) e paraju (Manilkara sp.). Para a determinação da massa específica aparente e da umidade das madeiras, utilizou-se a norma MB26/1940 da ABNT, e para a análise do ruído, utilizou-se a NR15 do Ministério do Trabalho e Emprego. As máquinas utilizadas foram: serra circular, desempenadeira, desengrossadeira, serra de fita, lixadeira de fita e destopadeira. Houve diferença significativa no estudo do nível de ruído provocado pelas seis máquinas com as seis madeiras a 5\% de significância. Verificou-se que o operador fica submetido a um nível médio de ruído de $86,5 \mathrm{~dB}(\mathrm{~A})$. Os testes de comparação de médias serviram para mostrar diferenças estatísticas entre as máquinas e a massa específica aparente das madeiras e para se verificar que os níveis de ruído emitidos pelas máquinas podem não diferir estatisticamente. $\mathrm{O}$ estudo da interação das madeiras nos níveis das máquinas indicou que a destopadeira gera um nível de ruído tão intenso que não há diferença entre as madeiras testadas.

Palavras-chave: Nível de ruído na usinagem; ambiente de trabalho; massa específica aparente da madeira.
\end{abstract}

\begin{abstract}
Influence of the wood density in the noise produced during the secondary processing of the wood. This research had as objective to analyze the noise produced during the secondary processing of distinct woods and its correlation with the mass specifies apparent. The used species were kiri (Paulpwnia sp), eucalipto1 (Eucalyptus grandis versus E. urophylla (híbrido urograndis)), eucalipto2 (Eucalyptus sp), angelim pedra (Hymenolobium petratum), cedro (Cedrela fissilis) e paraju (Manilkara sp.). The mass specifies apparent and moisture content of woods were determinate by norm MB26/1940 (ABNT) and to ergonomic analysis of noise was evaluated according to NR15 (Ministério do Trabalho). The chosen machines for analysis: cutter, buzzy saw, smoother, planer, tape saw and sander. It had significant difference in the study of noise level made by six machines with six woods at $5 \%$ of significance, moreover it was verified that the operator is exposed to an average noise level of $86.5 \mathrm{~dB}(\mathrm{~A})$. The comparison tests of averages were parameters to evidence statistical differences between machines and wood mass specifies apparent, also to verify that noise levels produced by machines there was no statistically difference. It was investigated the woods interaction on the same machine; as a result, the noise produced by cutter was so high with all woods which there was not statistical difference.

Keywords: Noise level in wood processing; work environment; wood mass specifies apparent.
\end{abstract}

\section{INTRODUÇÃO}

As operações de processamento secundário são aquelas realizadas logo após o desdobro principal e visam à redução das dimensões das peças ou o seu dimensionamento final, tanto no comprimento como na largura ou na espessura. Faz parte do cotidiano das indústrias de madeira serrada a utilização de espécies distintas, tornando-se ampla a gama de produtos serrados. Com relação ao 
processo, o fator humano muitas vezes é esquecido e mesmo negligenciado, algumas vezes por displicência e outras por falta de conhecimento das necessidades de adequação do trabalho ao trabalhador, pelo simples fato de o ser humano possuir grande capacidade para ajustar-se às condições de exposição que lhes são impostas, adaptando-se rapidamente às situações.

Para Iida (2005), a ergonomia é definida como a adaptação do trabalho ao homem. Uma condição de trabalho em que a ergonomia do processo não é observada leva a um baixo rendimento do trabalhador e da produção final. Quando um trabalhador está exposto a condições de trabalhos inadequadas, sua saúde torna-se vulnerável, aumentando os riscos de afastamentos por doenças ocupacionais.

O desconforto extremo acaba diminuindo o rendimento e aumenta a fadiga, o que leva muitas vezes o trabalhador ao estresse. Normalmente, os trabalhadores em marcenarias executam o trabalho em ambientes inadequados, expostos a elevados níveis de ruído. Esses fatores, segundo Fiedler et al. (2006), causam desconforto, aumentam o risco de acidentes e podem provocar danos consideráveis à saúde.

A madeira é originária de um sistema biológico complexo, tornando-se um material de extrema variabilidade. Sua ultraestrutura e composição química, bem como suas propriedades físicas e mecânicas, variam significativamente entre espécies, entre árvores de uma mesma espécie e, mesmo, entre diferentes partes de uma mesma árvore. A variabilidade geralmente encontrada dentro de uma árvore individual deve-se, provavelmente, às mudanças sofridas pelo câmbio durante o envelhecimento e a modificações impostas pelas condições ambientais (OLIVEIRA; SILVA, 2003).

As propriedades físicas são de extrema importância para a avaliação das características da madeira e seus diferentes fins aplicativos. A densidade representa a massa de madeira em determinado volume. Há uma significativa variação dessa propriedade entre espécies, dentro das espécies e mesmo dentro da árvore nos sentidos longitudinal e radial.

Como material anisotrópico, a madeira pode ser usinada em diferentes planos e diferentes maneiras, em função da direção e sentido de ataque das lâminas das máquinas em relação às fibras. Leitz (2001) afirmou que se pode processar a madeira na direção longitudinal e transversal, desde que se entenda a implicação dos planos de corte na resistência.

As pequenas empresas utilizam espécies de madeira diferentes nas mesmas máquinas e equipamentos da rotina de trabalho, sendo estes dotados de instrumentos cortantes que atuam diretamente na superfície dura e rígida da madeira. Mesmo espécies de baixa massa específica aparente induzem ao desgaste das lâminas e peças, que geram elevados níveis de ruído.

O ruído é uma mistura de sons cujas frequências diferem entre si, por valor inferior à discriminação em frequência do ouvido. Em excesso, prejudicam a sanidade física e psicológica do trabalhador, pois são de efeito aditivo, progressivo e irreversível, sendo necessário, por isso, qualificar e quantificar o ruído produzido por atividade do processo produtivo em madeiras de espécies variadas.

Entre os fatores ambientais que prejudicam os operadores das máquinas, o ruído pode ser considerado um dos principais. Além disso, um fator agravante é que a ciência ainda conhece pouco sobre as suas implicações na saúde ocupacional, em função da escassez de pesquisas (CUNHA; TEODORO, 2006).

O problema do ruído nasce da impossibilidade de se fabricarem máquinas industriais isentas de imperfeições, que produzam níveis baixos de ruído. Dessa forma, não é possível eliminá-lo, mas seu controle até um nível aceitável é possível. Ainda hoje, muitas máquinas são colocadas no mercado sem nenhuma preocupação por parte dos seus fabricantes com relação a determinadas características indispensáveis para a realização do trabalho com conforto e segurança (LIMA, 1998).

Esta pesquisa teve como objetivo analisar a influência da massa específica aparente da madeira no ruído produzido durante o processamento secundário.

\section{MATERIAL E MÉTODOS}

\section{Região de estudo}

A pesquisa foi desenvolvida na marcenaria do laboratório de Ciências da Madeira do Departamento de Engenharia Florestal do Centro de Ciências Agrárias da Universidade Federal do Espírito Santo, localizada no município de Jerônimo Monteiro, no sul do estado, no período de março a maio de 2007. 


\section{Madeiras analisadas}

As espécies utilizadas foram: kiri (Paulownia sp.), da família Scrophulariaceae; eucalipto 1 (Eucalyptus grandis versus E. urophylla (híbrido urograndis)), da família Myrtaceae; cedro (Cedrela fissilis), da família Meliaceae; angelim-pedra (Hymenolobium petraeum), da família Leguminosae; paraju (Manilkara sp.), da família Sapotaceae; e eucalipto 2 (Eucalyptus sp.), da família Myrtaceae.

\section{Máquinas utilizadas}

As máquinas comumente utilizadas no fluxograma de produção e analisadas nesta pesquisa foram: serra circular, desempenadeira, desengrossadeira, serra de fita, lixadeira de fita e serra destopadeira. Em cada máquina, teve-se o cuidado de comparar usinagens iguais, com o mesmo tipo de corte, mesmo tipo de serras utilizadas, velocidades de avanço e corte semelhantes, ângulo de incidência da madeira na máquina e ângulo de ferramentas iguais, adotados durante o processamento secundário da madeira.

A tabela 1 se refere à descrição técnica das máquinas avaliadas e a figura 1 mostra as máquinas utilizadas.

Tabela 1. Descrição técnica das máquinas avaliadas.

Table 1. Technical description of the analyzed machines.

\begin{tabular}{|c|c|}
\hline Máquinas & Descrição \\
\hline Serra circular & $\begin{array}{l}\text { Utilizada para serrar madeira ou derivados em cortes retos, por meio de uma serra circular } \\
\text { dentada acoplada em uma mesa de corpo fixo. Potência do motor de } 2 \mathrm{HP} \text { e rotação de } \\
3800 \mathrm{rpm} \text {. Utilizou-se uma serra de } 36 \text { dentes com } 25 \mathrm{~cm} \text { de diâmetro. }\end{array}$ \\
\hline Desempenadeira & Utilizada para nivelar a superfície da peça. Potência do motor de 3 CV. Possui 3 navalhas. \\
\hline Desengrossadeira & $\begin{array}{l}\text { Usada para se dimensionar a espessura das peças. Utilizada também para aplainar } \\
\text { superfícies, tornando-as uniformes. É constituída por navalhas e dois rolos de } \\
\text { alimentação, que funcionam automaticamente. Ao nível da mesa estão dispostos outros } \\
\text { dois rolos lisos que servem para o deslizamento da madeira. Potência do motor de } 5 \mathrm{CV} \text {, } \\
\text { trifásica. Possui } 2 \text { navalhas. }\end{array}$ \\
\hline Lixadeira & $\begin{array}{l}\text { Faz acabamentos de superfícies planas ou curvas. Elimina asperezas para que a peça possa } \\
\text { receber o acabamento final e possui lixa de cinta amarela de grã } 50 \text {. Compõe-se de duas } \\
\text { colunas ligadas entre si por uma cinta de lixa, entre as quais existe uma mesa fixa em que } \\
\text { é operada a peça de madeira, velocidade da cinta da lixa de } 3200 \mathrm{rpm} \text { e potência do motor } \\
\text { de } 1,5 \mathrm{CV} \text {. }\end{array}$ \\
\hline Serra de fita & $\begin{array}{l}\text { Possui uma versatilidade de trabalho muito grande, podendo realizar quaisquer tipos de } \\
\text { cortes retos ou irregulares, tais como círculos, ondulações, etc. Rotação dos volantes de } \\
600 \mathrm{rpm} \text {, diâmetro dos volantes } 800 \mathrm{~mm} \text {, espessura dos volantes } 50 \mathrm{~mm} \text { e potência do } \\
\text { motor trifásico } 5 \mathrm{CV} \text {. }\end{array}$ \\
\hline Serra destopadeira & $\begin{array}{l}\text { Utilizada para destopar e esquadrilhar madeira. Potência de } 5,5 \mathrm{CV} \text {. Utilizou-se serra de } \\
24 \text { dentes e } 40 \mathrm{~cm} \text { de diâmetro. }\end{array}$ \\
\hline
\end{tabular}

\section{Determinação da massa específica aparente e da umidade da madeira}

As peças foram colocadas em uma câmara climática a $25^{\circ} \mathrm{C}$ de temperatura e $60 \%$ de umidade relativa, permanecendo nessa condição até atingirem o equilíbrio higroscópico. Para determinação da massa específica aparente e da umidade das madeiras, foi utilizada a metodologia proposta pelo MB26 (1940) da Associação Brasileira de Normas Técnicas (ABNT).

\section{Análise dos níveis de ruído produzidos}

O ruído emitido em cada máquina foi analisado com o uso de um decibelímetro digital, sendo a coleta e análise de dados baseadas na legislação brasileira de atividades e operações insalubres (Segurança e Medicina do Trabalho, 2006), por meio da Norma Regulamentadora do Trabalho número 15 (NR 15).

O decibelímetro utilizado é da marca Instrutherm, modelo DEC - 460. O sensor foi posicionado próximo ao nível do ouvido do trabalhador enquanto ele operava a máquina. Os dados foram coletados em intervalos de 20 segundos durante toda a jornada de trabalho, sendo os valores (dB(A)) lidos e anotados para posteriormente ser feita uma média do nível de ruído no ambiente de trabalho na respectiva máquina. 


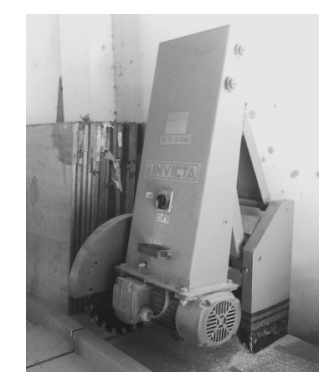

Serra destopadeira

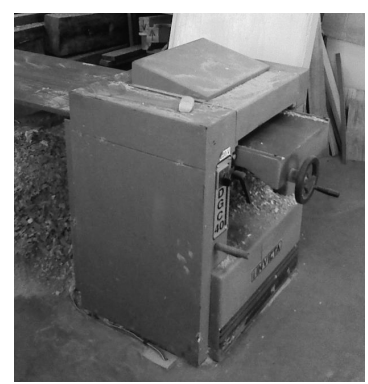

Desengrossadeira

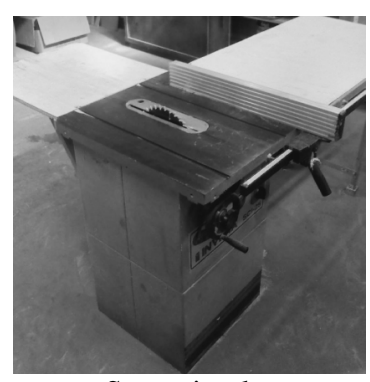

Serra circular

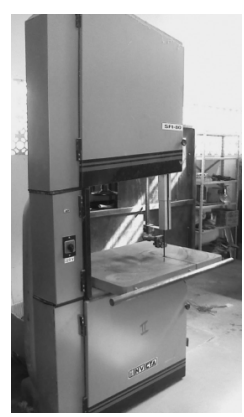

Serra de fita

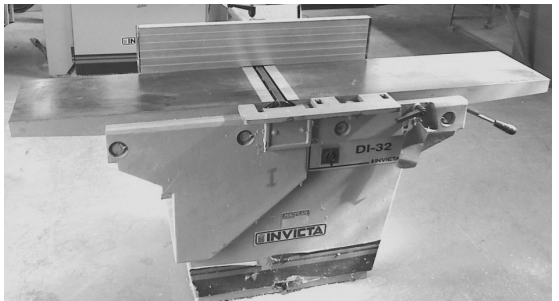

Desempenadeira

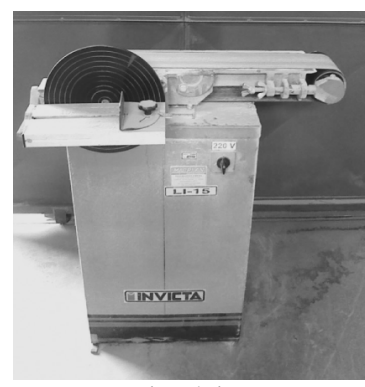

Lixadeira

Figura 1. Máquinas utilizadas no ciclo de trabalho nas marcenarias.

Figure 1. Machines used in work's cycle in joineries.

\section{Procedimento estatístico}

Os resultados obtidos dos níveis de ruído foram submetidos a uma análise de variância no experimento em fatorial, utilizando-se como fatores as máquinas e as madeiras, em seis níveis, através de suas respectivas massas específicas aparentes, utilizadas no processo de produção em um delineamento inteiramente casualizado (DIC) a 5\% de significância, determinando-se a interação ou não das máquinas em relação à massa específica aparente das madeiras. As médias das máquinas e da massa específica aparente das madeiras foram comparadas pelo teste de Tukey a 5\% de significância, quando estas apresentaram diferenças estatísticas significativas. Além da ANOVA, realizou-se o procedimento para o desenvolvimento de um modelo de regressão cúbico $\left(\mathrm{Y}=\mathrm{ax}+\mathrm{bx}^{2}+\mathrm{cx}^{3}\right)$ em função da variável independente massa específica aparente da madeira e variável dependente nível de ruído. Para todos os procedimentos estatísticos, foi utilizado o programa Estatístico SAEG 6.0.

\section{RESULTADOS E DISCUSSÕES}

\section{Massa específica aparente}

Os valores de massa específica aparente na faixa de umidade em equilíbrio em câmara climática a $60 \%$ de umidade relativa e $25^{\circ} \mathrm{C}$ de temperatura são apresentados na tabela 2.

Tabela 2. Valores médios de massa específica aparente nas faixas de umidade para as madeiras utilizadas.

Table 2. Average values of mass specifies apparent and moisture content in the wood used in this study.

\begin{tabular}{lcc}
\hline Espécie & Densidade $\left(\mathbf{g} / \mathbf{c m}^{\mathbf{3}}\right)$ & Umidade $\mathbf{( \% )}$ \\
\hline Paraju & 0,98 & $14 \%$ \\
Eucalipto 2 & 0,89 & $11 \%$ \\
Eucalipto 1 & 0,77 & $13 \%$ \\
Angelim-pedra & 0,74 & $12 \%$ \\
Cedro & 0,56 & $13 \%$ \\
Kiri & 0,33 & $11 \%$ \\
\hline
\end{tabular}

*: Climatização em $60 \%$ de umidade e temperatura de $25^{\circ} \mathrm{C}$. 
De acordo com a tabela 2, existe uma ampla faixa de massa específica aparente entre as madeiras utilizadas no processo de desdobro secundário na marcenaria, variando de alta massa específica aparente, como o paraju $\left(0,98 \mathrm{~g} / \mathrm{cm}^{3}\right)$, a baixa massa específica aparente como o kiri $\left(0,33 \mathrm{~g} / \mathrm{cm}^{3}\right)$. Também são observadas diferentes umidades no equilíbrio higroscópico para as distintas madeiras.

\section{Níveis de ruído}

As tabelas 3 e 4 mostram o resultado das análises dos níveis médios de ruído nas diferentes máquinas em relação às diferentes massas específicas aparentes das madeiras, e suas massas específicas aparentes em relação às máquinas de acordo com a interação significativa da análise de variância.

Tabela 3. Resultados do teste de comparações de média pelo teste de Tukey para a variável ruído $(\mathrm{dB}(\mathrm{A}))$ em função da relação das máquinas pela massa específica aparente das madeiras.

Table 3. Test results by comparisons of Tukey test for variable noise $(\mathrm{dB}(\mathrm{A}))$ on machinery by wood mass specifies apparent.

\begin{tabular}{|c|c|c|c|c|c|c|}
\hline \multirow{2}{*}{ Madeira } & \multicolumn{6}{|c|}{ Máquinas } \\
\hline & Serra circular & Desempenadeira & Desengrossadeira & Destopadeira & Serra de fita & Lixadeira \\
\hline 1 & $91,46 \mathrm{a}$ & $91,20 \mathrm{a}$ & $87,64 \mathrm{a}$ & $91,86 \mathrm{~A}$ & $82,66 \mathrm{a}$ & $83,93 \mathrm{a}$ \\
\hline 2 & $91,47 \mathrm{a}$ & $90,01 \mathrm{ab}$ & $87,04 \mathrm{a}$ & $91,67 \mathrm{~A}$ & $82,21 \mathrm{a}$ & $83,64 \mathrm{a}$ \\
\hline 3 & $90,51 \mathrm{a}$ & $91,00 \mathrm{a}$ & 86,21 a & $91,34 \mathrm{~A}$ & $80,71 \mathrm{ab}$ & $83,87 \mathrm{a}$ \\
\hline 4 & 89,96 a & $91,76 \mathrm{a}$ & $86,21 \mathrm{a}$ & $92,36 \mathrm{~A}$ & $79,61 \mathrm{~b}$ & $83,06 \mathrm{a}$ \\
\hline 5 & $87,56 b$ & $88,16 b$ & $87,2 \mathrm{a}$ & $91,43 \mathrm{~A}$ & $81,20 \mathrm{ab}$ & $82,89 \mathrm{a}$ \\
\hline 6 & $86,17 \mathrm{~b}$ & $85,69 \mathrm{c}$ & $86,71 \mathrm{a}$ & $91,70 \mathrm{~A}$ & $78,90 \mathrm{~b}$ & $83,21 \mathrm{a}$ \\
\hline Média & 89,52 & 89,64 & 86,84 & 91,73 & 80,88 & 83,43 \\
\hline
\end{tabular}

Tabela 4. Resultados do teste de comparações de média pelo teste de Tukey para a variável ruído $(\mathrm{dB}(\mathrm{A}))$ gerado da relação da massa específica aparente das madeiras através do uso em diferentes máquinas.

Table 4. Test results by comparisons of Tukey test for variable noise (dB (A)) on machinery by wood mass specifies apparent and its relation in different machines.

\begin{tabular}{lcccccc}
\hline \multirow{2}{*}{ Máquinas } & \multicolumn{7}{c}{ Madeiras } \\
\cline { 2 - 7 } & Eucalipto 2 & Kiri & Paraju & Eucalipto 1 & Angelim-pedra & Cedro \\
\hline 1 & $91,34 \mathrm{a}$ & $91,70 \mathrm{a}$ & $91,86 \mathrm{a}$ & $92,36 \mathrm{a}$ & $91,67 \mathrm{a}$ & $91,43 \mathrm{a}$ \\
2 & $91,00 \mathrm{a}$ & $85,69 \mathrm{~b}$ & $91,20 \mathrm{a}$ & $91,76 \mathrm{ab}$ & $90,01 \mathrm{a}$ & $88,16 \mathrm{~b}$ \\
3 & $90,51 \mathrm{a}$ & $86,17 \mathrm{~b}$ & $91,46 \mathrm{a}$ & $89,96 \mathrm{~b}$ & $91,47 \mathrm{a}$ & $87,56 \mathrm{~b}$ \\
4 & $86,21 \mathrm{~b}$ & $86,71 \mathrm{~b}$ & $87,64 \mathrm{~b}$ & $86,21 \mathrm{c}$ & $87,04 \mathrm{~b}$ & $87,20 \mathrm{~b}$ \\
5 & $83,87 \mathrm{c}$ & $83,21 \mathrm{c}$ & $83,93 \mathrm{c}$ & $83,06 \mathrm{~d}$ & $83,64 \mathrm{c}$ & $82,69 \mathrm{c}$ \\
6 & $80,71 \mathrm{~d}$ & $78,90 \mathrm{~d}$ & $82,66 \mathrm{c}$ & $79,61 \mathrm{e}$ & $82,21 \mathrm{c}$ & $81,20 \mathrm{c}$ \\
\hline Média & 87,27 & 85,40 & 88,13 & 87,16 & 87,67 & 86,37 \\
\hline
\end{tabular}

Máquinas: 1: Destopadeira; 2: Desempenadeira; 3: Serra circular; 4: Desengrossadeira; 5: Lixadeira; 6: Serra de fita.

De acordo com a tabela 3, verifica-se que o operador fica submetido a um nível geral médio de ruído de $87,04 \mathrm{~dB}(\mathrm{~A})$. A máquina de maior ruído produzido em média para todas as madeiras em estudo foi a serra destopadeira, com $91,73 \mathrm{~dB}(\mathrm{~A})$. A serra de fita e a lixadeira foram as máquinas que se enquadraram dentro do limite permitido pela legislação brasileira com manuseio de espécies distintas, que é de $85 \mathrm{~dB}(\mathrm{~A})$ para uma jornada de trabalho de 8 horas diárias, sendo, respectivamente, $80,88 \mathrm{~dB}(\mathrm{~A})$ e $83,43 \mathrm{~dB}(\mathrm{~A})$. Os ruídos intensos tendem a prejudicar a concentração mental e certas tarefas que exigem atenção ou velocidade e precisão de movimentos.

No estudo dos efeitos da interação máquina versus madeira, observou-se que houve diferença significativa entre as seis máquinas e as seis madeiras a 5\% de significância. Procedeu-se à análise de cada um dos níveis do fator madeira dentro de cada um dos níveis máquina e o estudo do fator máquina dentro dos níveis madeira. Desse modo, foi necessária a utilização de um teste de comparações de médias para avaliação das similaridades e diferenças existentes entre as máquinas e as madeiras. 
O teste de comparações de médias serviu para mostrar diferenças estatísticas entre as máquinas e a densidade das madeiras e verificar que os níveis de ruído emitidos pelas máquinas podem não diferir estatisticamente.

A análise feita a partir dos dados da tabela 3 permite afirmar que para a serra circular a maior emissão de ruído foi expressa pelas madeiras de paraju, angelim-pedra, eucalipto 2 e eucalipto 1, que apresentaram os maiores valores de massa específica aparente e que não diferiram significativamente. $\mathrm{O}$ cedro e o kiri, madeiras com menor emissão de ruído entre as madeiras em questão, diferiram estatisticamente das demais e, mesmo assim, indicaram níveis de ruído acima do permitido pela NR15, de $85 \mathrm{~dB}(\mathrm{~A})$ para um turno de oito horas de trabalho.

Ainda de acordo com tabela 3, para a desempenadeira, observa-se que os maiores níveis de ruído foram determinados pelo paraju, eucalipto 2 , eucalipto 1 e angelim-pedra, que não diferiram significativamente entre si ao nível de $5 \%$ de probabilidade, sendo que este último não diferiu significativamente do cedro. O kiri diferiu estatisticamente das demais madeiras e apresentou a menor emissão de ruído acima do tolerável pela norma. Para a serra de fita, o teste de Tukey (Tabela 3) indicou que o paraju, o angelim-pedra, o cedro e o eucalipto 2 não diferiram entre si, e os dois últimos não diferiram do eucalipto 1 . Os maiores níveis de ruído foram determinados pelas madeiras de paraju e angelim-pedra, e os menores pelo eucalipto 1 e kiri.

Para as três outras máquinas (desengrossadeira, destopadeira e lixadeira), não houve diferenças significativas entre os níveis de ruído na relação apresentada pelas madeiras.

Os maiores níveis de ruído emitidos pelas densidades das madeiras foram encontrados na destopadeira, sendo necessário uma análise particular na confecção dessa máquina para redução de ruído na fonte.

Como apresentado na tabela 4, quando utilizada a madeira de eucalipto 2, os maiores níveis de ruído ocorreram na destopadeira, na desempenadeira e na serra circular, que não diferiram estatisticamente. A desengrossadeira, a lixadeira e a serra de fita diferiram entre si e das demais máquinas, sendo a menor emissão de ruído ocasionado pela serra de fita, que apresentou valor dentro dos limites permitidos.

Para fins de utilização da madeira de kiri, a maior emissão de ruído ocorreu na destopadeira, que diferiu estatisticamente de todas as outras máquinas. Já a serra de fita apresentou o menor nível de ruído, que gerou o menor valor da relação entre todas as madeiras e os níveis de máquinas.

Para a madeira de paraju (Tabela 4), o maior nível de ruído foi provocado pela destopadeira, pela desempenadeira e pela serra circular, não se diferenciando entre si pela estatística utilizada. Já a desengrossadeira diferiu das máquinas que apresentaram maiores a menores níveis de ruído, sendo estes indicados pela lixadeira e pela serra de fita, que não diferiram significativamente entre si e apresentaram valores de ruído dentro do permitido pela norma NR15.

A madeira de eucalipto 1 demonstrou a maior diferença em relação aos índices de ruídos apresentados pelas máquinas no teste de Tukey. Os maiores índices de ruído foram da destopadeira e da desempenadeira, sendo esta última não diferente estatisticamente da serra circular. A desengrossadeira, a lixadeira e a serra de fita diferiram estatisticamente das máquinas anteriores e entre si, sendo o menor índice de ruído da serra de fita, que apresentou índices toleráveis pela norma NR15.

Já para a madeira de angelim-pedra (Tabela 4), a destopadeira, a desempenadeira e a serra circular não apresentaram diferenças significativas, mas foram estatisticamente diferentes da desengrossadeira, da lixadeira e da serra de fita, sendo as duas últimas estatisticamente iguais. A maior emissão de ruído foi da destopadeira, e a menor, da serra de fita.

Pelo apresentado no teste de Tukey (Tabela 4), quando utilizada a madeira de cedro, o maior valor de ruído foi da destopadeira, que diferiu estatisticamente de todas as demais máquinas. Os menores índices de ruído foram da serra de fita e da lixadeira, que não diferiram significativamente.

Em estudo da interação entre as máquinas e os níveis de madeira (Tabela 3), a madeira que apresentou o maior índice de ruído foi o paraju, apresentando a maior massa específica aparente dentre as espécies analisadas, podendo ser um fator de resistência da máquina ao seu processamento, que gera maior nível de ruído. No estudo da interação das madeiras no nível máquina (Tabela 4), a máquina que emitiu o maior ruído foi a destopadeira, podendo ser dito que o nível de ruído da máquina é tão intenso que não há diferença entre as madeiras testadas, mesmo estas apresentando valores de massa específica aparente diferentes.

Procurou-se ajustar modelos de regressão correlacionando o nível de ruído com a massa específica aparente das madeiras (Tabela 5). 
Tabela 5. Modelos cúbicos de regressão e Valores de Coeficiente de Determinação (R2) para níveis de ruído obtidos em função da massa específica aparente da madeira.

Table 5. Models cubic regression and values of coefficient of determination $\left(\mathrm{R}^{2}\right)$ to noise level made on the basis of wood mass specifies apparent.

\begin{tabular}{llc}
\hline Máquinas & \multicolumn{1}{c}{ Modelo } & $\mathbf{R}^{\mathbf{2}(\%)}$ \\
\hline Desempenadeira & $\mathrm{R}=111,628-149,390 * \mathrm{D}+256,638 * \mathrm{D} 2-128,211 * \mathrm{D} 3$ & 54,4 \\
Desengrossadeira & $\mathrm{R}=46,2075+219,180 * \mathrm{D}-348,930 * \mathrm{D} 2+171,906 * \mathrm{D} 3$ & 29,8 \\
Serra circular & $\mathrm{R}=77,8009+38,4069 * \mathrm{D}-46,9850 * \mathrm{D} 2+22,4429 * \mathrm{D} 3$ & 29,1 \\
Destopadeira & $\mathrm{R}=84,7197+37,4114 * \mathrm{D}-58,6811 * \mathrm{D} 2+28,4316 * \mathrm{D} 3$ & 14,3 \\
Serra de fita & $\mathrm{R}=16,3060+333,831 * \mathrm{D}-520,730 * \mathrm{D} 2+254,400 * \mathrm{D} 3$ & 26,5 \\
Lixadeira & $\mathrm{R}=90,4791-37,9638 * \mathrm{D}+56,4075 * \mathrm{D} 2-24,9781 \mathrm{D} 3$ & 22,6 \\
\hline
\end{tabular}

De acordo com a tabela 5, tentou-se estabelecer um modelo cúbico de regressão para a relação do ruído (variável dependente) em função das massas específicas aparentes das madeiras (variável independente) para cada máquina, sendo o resultado não expressivo, com valores de coeficiente de determinação $\left(\mathrm{R}^{2}\right)$ baixos (menores que $30 \%$ para a maioria das máquinas, exceto para a desempenadeira, com $\mathrm{R}^{2}$ de 54\%) para os níveis de ruído de todas as máquinas em relação à massa específica aparente das madeiras. Outros fatores, como a estrutura anatômica, o teor de umidade e a composição química da madeira devem ser levados em consideração quando se relaciona massa específica aparente e níveis de ruído. Além disto, o modelo de regressão apresentado pela análise de variância foi significativo em quase todos os casos, exceto para a destopadeira, por possuir um valor para $\mathrm{F}$ calculado muito baixo, próximo da não significância. Essa análise indica que os modelos não possuem um $\mathrm{R}^{2}$ suficiente para que a variável ruído seja explicada pela equação de regressão. Portanto, levando em consideração os modelos propostos e os valores de $\mathrm{R}^{2}$, os níveis de ruído não são influenciados (produzidos) somente pela massa específica aparente da madeira sofrendo interferência de outros fatores no ruído desenvolvido pelas máquinas.

A figura 2 indica os níveis de ruído $(\mathrm{dB}(\mathrm{A}))$ produzidos nas diferentes madeiras e suas massas específicas aparentes nas máquinas comumente utilizadas no sistema produtivo das marcenarias.

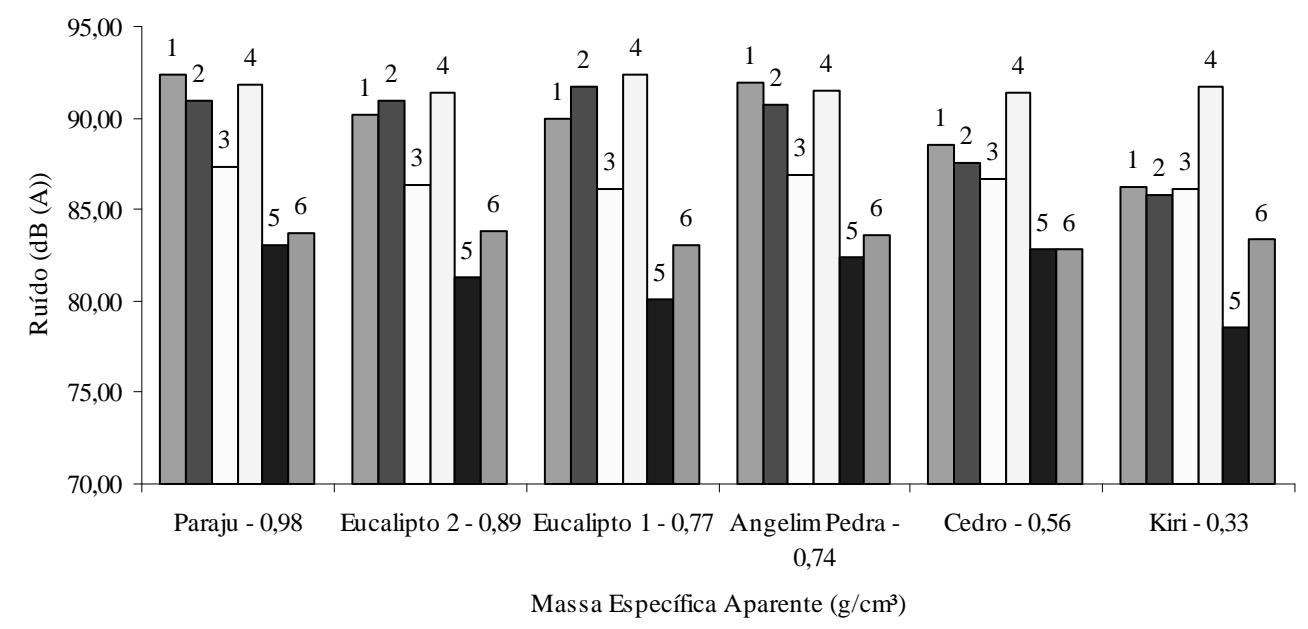

Figura 2. Níveis de ruído $(\mathrm{dB}(\mathrm{A}))$ nas diferentes madeiras e suas massas específicas aparentes, nas máquinas comumente utilizadas no sistema produtivo das marcenarias.

Figure 2. Noise level $\mathrm{dB}(\mathrm{A})$ the various woods and mass specifies apparent, with the chosen machines for analysis.

Legenda: 1: Serra circular; 2: Desempenadeira; 3: Desengrossadeira; 4: Destopadeira; 5: Serra de fita; 6: Lixadeira; 7: Limite de exposição de ruído permitido pela NR15.

A destopadeira foi a máquina com ruído extremamente elevado em todas as madeiras analisadas, apresentando o maior nível de ruído médio $(92,36 \mathrm{~dB}(\mathrm{~A})$ ), quando utilizada a madeira do híbrido urograndis. Para essa dosagem de ruído, permite-se uma exposição máxima de 3 horas e 3 minutos, 
cabendo ressaltar que a jornada de trabalho diária é de 8 horas. Essa exposição prejudica a concentração mental, a atenção e a velocidade e precisão de movimentos. Portanto, há a necessidade de proteção dos ouvidos do trabalhador. A serra de fita e a lixadeira foram as máquinas com menores níveis de ruído, e o kiri a madeira com os menores níveis de ruído em todas as máquinas analisadas, com exceção da destopadeira.

\section{CONCLUSÕES}

De acordo com os resultados apresentados, pode-se concluir que:

- As espécies influem nos níveis de ruído produzidos pela serra circular, desempenadeira e serra de fita.

- As espécies não influem na emissão de ruído produzido pela lixadeira, destopadeira e desengrossadeira.

- O nível de ruído é afetado pelo efeito máquina e madeira.

- O modelo cúbico de regressão para a relação do ruído em função das massas específicas aparentes das madeiras para cada máquina é significativo, exceto para a destopadeira, embora apresentem $\mathrm{R}^{2}$ baixos, não explicando bem a relação ruído versus massa específica aparente das madeiras utilizadas neste estudo.

\section{REFERÊNCIAS}

ASSOCIAÇÃO BRASILEIRA DE NOMAS TÉCNICAS (ABNT). MB-26/40: ensaios físicos e mecânicos da madeira. Rio de Janeiro: 1940. 16 p.

CUNHA, J. P. A. R.; TEODORO, R. E. F. Avaliação do nível de ruído em derriçadores e pulverizadores motorizados portáteis utilizados em lavouras de café. Bioscience Journal, Uberlândia, v. 22, n. 3, p. 7177. 2006

FIEDLER, N. C., RODRIGUES, T. O, MEDEIROS, M. B. Avaliação das condições de trabalho, treinamento, saúde e segurança de brigadistas de combate a incêndios florestais em unidades de conservação do DF. Revista Árvore, Viçosa, MG, v. 30, n 1, p. 55-63, 2006.

IIDA, I. Ergonomia: projeto e produção. 9. ed. São Paulo: Edgard Blücher, 2005. 465p.

LEITZ. Das leitz lexikon. 3. ed. Unterschneidheim: [S.1.: s.n.], 2001.Não paginado.

LIMA, J.S.S. Avaliação da força de arraste, compactação do solo, e fatores ergonômicos num sistema de colheita de madeira, utilizando os tratores florestais "Feller-Buncher" e "Skidder". 132 f. Tese (Doutorado em Ciência Florestal) - Universidade Federal de Viçosa, Viçosa, MG, 1998.

OLIVEIRA, J. T. S.; SILVA, J. DE C.; Variação radial da retratibilidade e densidade básica da madeira de Eucalyptus saligna Sm. Revista Árvore, Viçosa, MG, v. 27, n. 3 p. 381-385. 2003

SEGURANÇA e medicina do trabalho: lei n. 6.514, de 22 de dezembro de 1977, normas regulamentadoras (NR) aprovadas pela Portaria n. 3.214, de 8 de junho de 1978, normas regulamentadoras rurais (NRR) aprovadas pela Portaria n. 3.067, de 12 de abril de 1988, indices remissivos. 56. ed. São Paulo, Atlas, 2006. 771 p. (Manuais de Legislação Atlas, 16). 